\title{
The Experiences of Mobile Populations About Malaria Control in Southeastern Iran Using the PEN-3 Cultural Model: A Qualitative Study
}

\author{
Ahmad Raiesi ${ }^{1}$, Seyed Mohammad Hashemi-Shahri ${ }^{2,}{ }^{*}$, Mohammad Mehdi Gouya ${ }^{1}$, Alireza \\ Ansari-Moghaddam (iD) ${ }^{2}$, Fariba Shahraki-Sanavi (iD) ${ }^{2}$, Mahdi Mohammadi (iD) ${ }^{2}$, Hasan Okati Aliabad (iD) ${ }^{2}$, \\ Seyed Mehdi Tabatabaei ${ }^{2}$, Mehdi Zanganeh $\mathbb{D}^{2}$ and Khadijeh Kalan Farmanfarma ${ }^{2}$ \\ ${ }^{1}$ Centre for Disease Control \& Prevention, Ministry of Health and Medical Education, Tehran, Iran \\ ${ }^{2}$ Health Promotion Research Center, Zahedan University of Medical Sciences, Zahedan, Iran \\ "Corresponding author: Health Promotion Research Center, Zahedan University of Medical Sciences, Dr. Hesabi Sq., Postal Code: 9817667993, Zahedan, Iran. Tel: +98-9151413898, \\ Email: dr.sm.hashemishahri@gmail.com
}

Received 2018 July 02; Revised 2018 November 04; Accepted 2018 November 07.

\begin{abstract}
Objectives: Although malaria is in the elimination phase in Iran, cases imported from Afghanistan and Pakistan as malaria-endemic regions is challenging. Therefore, the present study investigates the experiences of mobile populations about malaria control in Southeastern Iran.

Methods: A qualitative study was conducted in October 2015. Participant selection was purposive and criteria-based, and a total of 70 migrants and mobile population were selected from Sistan and Baluchistan province, southeast of Iran. Semi-structured indepth interviews were conducted with all of the participants using ten guide questions based on the concepts of the PEN-3 model to examine the views and experiences of the participants about malaria during their travels. The PEN-3 model emphasizes the culture of preventive behaviors or health-promoting behaviors. Content analysis was used for data analysis.

Results: According to the PEN-3 model, the most important cultural impediments were the false beliefs about the usefulness of herbal medicines for the treatment of the disease (negative perception), the wrong attitude of being protected from the disease due to holding certain jobs (negative perception), the belief in destiny and God's will with respect to the incidence of diseases (negative enabler), and eating native plants for the prevention of the disease (existential nurturer).

Conclusions: Malaria prevention program should focus on the cultural characteristics of immigrants for effective interventions to control malaria.
\end{abstract}

Keywords: Malaria, Immigrant, Iran, PEN-3 Model, Culture

\section{Background}

Malaria is a parasitic protozoan disease caused by four species of Plasmodium, each of which is distributed in certain regions of the world (1). According to the World Health Organization (WHO) report in 2010, malaria is the most important parasitic disease across the world and is considered a national public health problem in 108 countries with a costly pursuit (2). Moreover, malaria is the fifth global cause of death from infectious diseases (3). Approximately 3.3 billion people across the world are at risk of malaria (4). A global estimate of 216 million malaria cases occurred in 2016 compared with 237 million cases in 2010 and 211 million cases in 2015 (5). The United Nations proposed plans for a $50 \%$ reduction in the incidence of malaria by 2015 , indicating the importance of the battle against malaria and its control (6).
The eastern Mediterranean region is one of the malaria-plagued regions across the world affected by endemic malaria (7). About $60 \%$ of the populations in this region are at risk of malaria (8). Iran is also a malariaendemic area with its diverse climate (9). About 95\% of the cases with malaria reported in Iran come from three provinces of Sistan and Baluchistan (S and B), Hormozgan and Kerman (10) of which $S$ and B accounts for approximately $50 \%$ of the whole cases. It should be noted that $80 \%$ of malaria cases in S and B occur in Southern districts, including Iranshahr, Nikshahr, and Chabahar (11).

Iran is one of the regions in the elimination phase. One of the main challenges is long borders with Afghanistan and Pakistan as endemic malaria regions. Population mobility from high-risk to low-risk areas is a major threat to eliminate the disease (12) and to improve the eradication programs (13). Malaria transmission is mainly dependent 
on traveling from endemic to non-endemic areas $(14,15)$ and also traveling to endemic countries (16-18), where susceptible people are at greater risk of inflicting malaria (19, 20). Studies conducted in Iran have also reported higher infection rates in migrant and mobile population than in Iranian nationals. Accordingly, population movement leads to a sudden increase in the incidence of malaria and the annual parasite index and turns uninfected areas with a potential for transmission or inactive areas to areas with the local transmission $(21,22)$. There is evidence that Afghan and Pakistani migrants account for one-third of malaria cases in Iran $(23,24)$. Therefore, $S$ and B province is at high risk of malaria due to sharing a long border with these countries (25).

PEN-3 cultural model has been effectively used for modeling the cultural characteristics of immigrants and native residents in malaria intervention programs (26) and the barriers to the prevention and treatment of malaria (27).

\section{Objectives}

The present study was conducted to investigate the relationship between migrant's cultures and malaria in a mobile population in the border cities of $S$ and B province using the PEN-3 cultural model.

\section{Methods}

The present directed content analysis study is a qualitative study in design and uses maximum variation purposive sampling to examine individuals with different views and experiences of malaria during their travels, including seasonal farmers from Pakistan, and Afghanistan, fuel smugglers, members of the religious missionaries, and residents with family or relatives in Iran's neighboring countries.

The study inclusion criteria consisted of willing to participate in the study, being able to express the experiences of migration, and making multiple trips every year whether inside or outside the borders. Participant selection was largely purposive and criteria-based. Sampling continued until data saturation occurred and a total of 70 subjects were selected. Data were collected in rural areas in several passive posts at the zero point borders of $S$ and B province. The urban sampling areas included Pishin, Rimdan, and Keshtegan regions in Saravan district along with BahuKalat area in Chabahar district. Healthy volunteers in each region were first approached and were asked for engaging in the interviews. Then members of their community were recruited to participate in the study. Only individuals who did not wish to participate were excluded. Semi-structured in-depth interviews were conducted. There were some questions about sociodemographic characteristics, halfway rest places, duration of journey, clothing, nutrition, sleep, and rest while traveling along with guide questions based on the concepts of the PEN-3 model, including how is malaria defined in your area? How may a person get malaria? How is malaria prevented in your area? How can people avoid malaria during trips? What are the threats if people do not use preventive methods? What are the costs and burdens imposed on people by taking precautionary measures? What are examples of measures taken for controlling the symptoms of the disease? What kind of problems people have with regard to malaria disease in your living area? How is the quality of services provided by healthcare facilities? What do your family, friends, and local leaders think about malaria? What cultural beliefs do you have about malaria in your region? In the end, how your people can assure their health regarding living area conditions?

The PEN-3 model includes three interrelated dimensions of cultural identity (person, extended family, neighborhood), relationships and expectations (perception, enablers, nurturers), and cultural empowerment (positive, existential, negative) in the form of nine factors (28). This model is suitable for use in special populations and minority groups.

After obtaining the necessary permissions from the authorities, the researchers visited the research settings accompanied by locals (local health workers within the region) and introduced themselves and tried to gain the trust of the study subjects. Subsequently, they proceeded to interview the participants in private after obtaining their informed written consent and ensuring that they had the code of ethics. The interviews were held over one session in a quiet and private area in work or living place of the participants. Each interview lasted from 30 to 45 minutes based on each participant's degree of patience and cooperation. All the interviews were recorded and the researcher took simultaneous notes. At the end of each day, the interviews were transcribed verbatim by the researchers after they were played several times. Content analysis was used for data analysis. Responses were analyzed to identify themes that addressed the study objectives and emerging themes. Emergent themes were categorized using the PEN-3 model. Coded data were fitted into one of the following dimensions: cultural identity (person, extended family, neighborhood); relationships and expectations (perception, enablers, nurturers); and cultural empowerment (positive, existential, negative). Quotes that best described the various themes were included to support quantitative findings.

Based on this method, the researcher reviewed the par- 
ticipants' descriptions to be able to better sympathize with them and then extracted the most relevant statements regarding the phenomenon and developed the categories and clusters. Combining all opinions deduced, finally, yielded a comprehensive and detailed description of the phenomenon under study. The various statements were compared based on differences and similarities and sorted based on the PEN-3 model.

\section{Results}

The present qualitative study was conducted on $70 \mathrm{mi}-$ grants in the southeast of Iran. The majority of the participants were male, illiterate or primary school graduates, and farmworkers or sailors (Table 1 ).

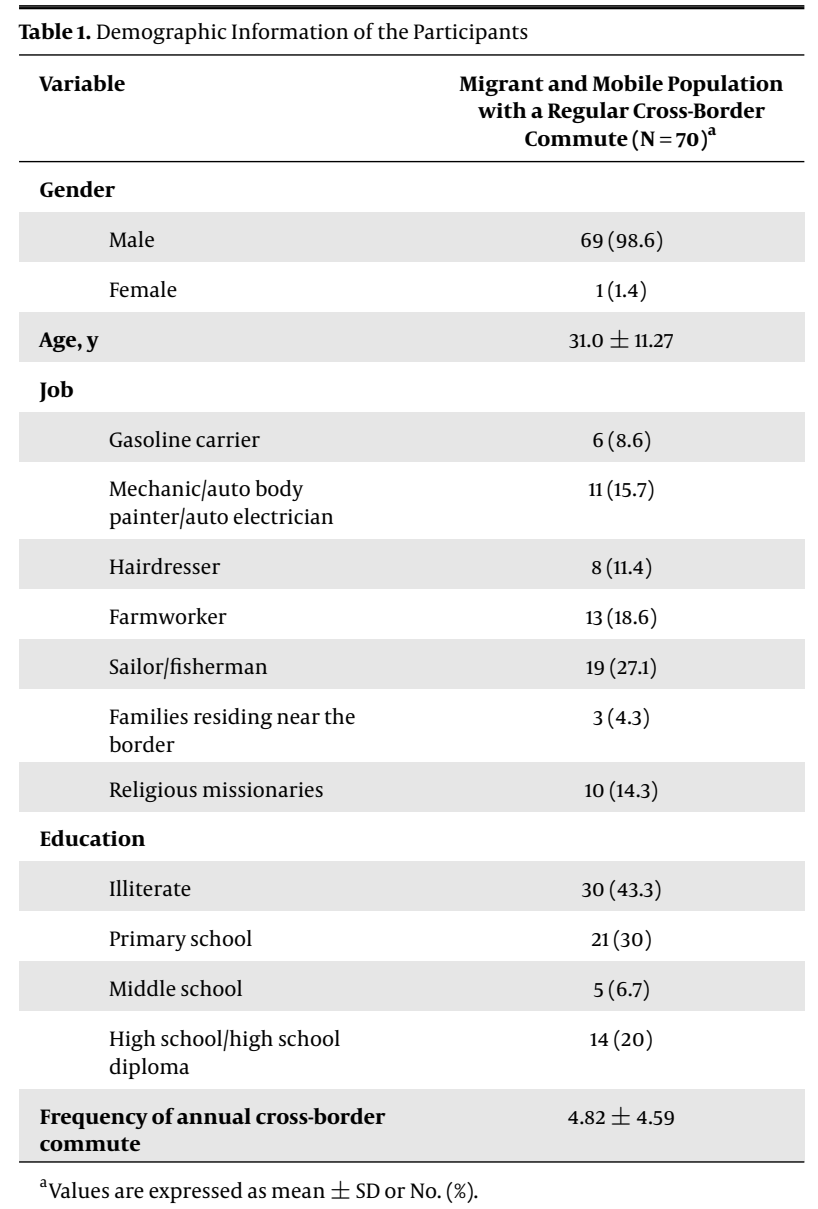

Table 2 assesses the interviews conducted based on the PEN-3 model, including relationships and expectations (RE) and cultural empowerment (CE) in the form of nine factors.

Perceptions are comprised of knowledge, attitudes, beliefs, and values. As examples of the participant's positive perceptions are as follows: a boat captain said, "On this trip, one of the sailors got down with fever and could not work for two days. We came back to the shore and dropped him off to go visit a clinic". An auto body painter said, "I got malaria. The problem is, you tremble a lot and then cover up under a blanket to keep warm. You cannot eat well. I took Pakistani medicine for two days but everything got worse. We informed the Health House and then a health worker came and took a blood sample from me and gave me medicines".

As an example of the existing perceptions expressed, an electrician said, "If you do not observe personal hygiene and go easy on washing yourself and your clothes, mosquitoes will bite you and you will get malaria”. A member of the religious missionaries said, "If you get malaria, you should avoid lemon and bad food. You should not leave the house very often and should take drugs to get cured, praise be to Allah".

A painter said, "In Pakistan, people take a pack of medications once a year and avoid malaria altogether. There is no need to go to the doctor". One of the members of the religious missionaries also stated, "We once went to Pakistan; there, they burnt a kind of medicine that kept the mosquitoes and malaria away". The fuel smugglers also believed that "mosquitoes do not bite us because our hands and clothes always smell like gasoline". The sailors believed that "When at sea, there is no need to use mosquito nets. There are no mosquitoes at sea".

The positive enablers included the provision of free services, supportive government policies, and frequent follow-up by the health workers. One of the farmworkers said, "One of the guys at the farm had chills, nausea, and body ache. He was down with a fever for three days. We went to a clinic. They took blood from him and said he had malaria".

A lot of negative nurturers were also described by some of the participants. For example, a mechanic said, "I always go out and come back safe and healthy. I pray and work. I eat Persian food, so I do not get malaria. I believe in destiny and God's will. If he wills, we will get malaria. All diseases get to us by His will". A member of the religious missionaries said, "The sewage system here is neglected and that is the worst thing they could do. Protecting the water is the first step because insects grow in it and can cause disease". An auto body painter said, "On the way to work, we wrap ourselves up in a veil to avoid being bitten by mosquitoes". Another member of the religious missionaries said, "Brewing willow tree root is good for the treatment of malaria. Although even if the drugs are effective, it is only God's will. No one comes to our communities to give us malaria prevention tools. Poverty should be eradicated in here and mosquito nets should be distributed among the people. 


\begin{tabular}{|c|c|c|c|}
\hline \multirow{2}{*}{$\begin{array}{l}\text { Relationships and } \\
\text { Expectations (RE) }\end{array}$} & \multicolumn{3}{|c|}{ Cultural Empowerment (CE) } \\
\hline & Positive & Existential & Negative \\
\hline Perceptions & $\begin{array}{l}\text { (i) Awareness about the disease and its } \\
\text { symptoms, prevention, and treatment. (ii) } \\
\text { Responding appropriately to symptoms of the } \\
\text { disease when observed in oneself or those } \\
\text { around by visiting the Health House or } \\
\text { informing the health workers. }\end{array}$ & $\begin{array}{l}\text { (i) Believing that certain } \\
\text { food restrictions help } \\
\text { prevent the disease. (ii) } \\
\text { Observing personal hygiene. }\end{array}$ & $\begin{array}{l}\text { (i) Having the wrong attitude of being protected } \\
\text { from the disease by their job. (ii) False beliefs } \\
\text { about herbal medicine's ability to treat the } \\
\text { disease. }\end{array}$ \\
\hline Enablers & $\begin{array}{l}\text { (i) House-to-house training by healthcare } \\
\text { assistants. (ii) Active case-finding by health } \\
\text { workers in the areas covered by the Health } \\
\text { House }\end{array}$ & $\begin{array}{l}\text { (i) Believing in observing } \\
\text { religious and juridical } \\
\text { principles for maintaining } \\
\text { health }\end{array}$ & $\begin{array}{l}\text { (i) Long distance or poor road access to the } \\
\text { Health House; Poor distribution of prevention } \\
\text { tools by health workers to those seeking } \\
\text { temporary residence in the area. (ii) Extremely } \\
\text { poor public health due to poor coverage of the } \\
\text { rural areas by the municipality. (iii) Financial } \\
\text { problems and inability of border residents to } \\
\text { buy and install mosquito nets, air conditioners, } \\
\text { etc. (iv) Hot and humid weather. (v) Believing in } \\
\text { destiny and God's will with regard to the } \\
\text { incidence of disease }\end{array}$ \\
\hline Nurturers & $\begin{array}{l}\text { (i) Immediate diagnosis and treatment of } \\
\text { patients in Health Houses. (ii) Follow-up of the } \\
\text { patients by health workers and their support at } \\
\text { home. (iii) Support of the patients by families } \\
\text { and health workers }\end{array}$ & $\begin{array}{l}\text { (i) Eating native plants to } \\
\text { prevent the disease }\end{array}$ & (i) Lack of support for patients by employers \\
\hline
\end{tabular}

Larger nets are best because they allow for everyone to be protected during their sleep". A hairdresser said, "I do not have a mosquito net. I hope I will not get malaria. They gave me a mosquito net. I took it home to Pakistan and gave it to my family". A farmworker said, "Constantly opening up and closing a mosquito net becomes a burden". Another farmworker said, "A mosquito net is good for one month and then the mosquitoes come back the next month and manage to pass through the holes. A mosquito net usually lasts six good months and then gets torn". A sailor said, "If they spray the boat twice a year, insects and mosquitos will disappear. If they give us mosquito nets, we will not get malaria. There are 25 of us on the boat and we only have one mosquito net". Another sailor said, "They do not care much about the sailors. The only doctors who visit us are vets. They should give us at least one mosquito net to hang above the room and sleep inside".

The positive nurturers expressed by the participants included support from the family and friends, the immediate diagnosis and treatment of the patients, and education via the mass media.

The existential nurturers expressed included the local treatment of the disease and eating medicinal plants. A mechanic said, "White seeds grown in the mountains that help prevent malaria if you eat them. They purify your blood and mosquitoes will not bite you anymore. I eat these seeds every morning and every night and so do not get malaria. Everyone can be his own doctor".

Some of the statements made by the participants were indicative of negative nurturers. A farmworker said,
"Health workers visit here, but some people fear that they are accompanied by a police officer and so run away when observing them".

\section{Discussion}

In general, the incidence of malaria has declined in recent years; however, there are reports of local transmission in S and B province, perhaps due to population mobility and migration, and the residents' jobs that require cross-border movement. Bandar Abbas is always at risk of malaria epidemics because it is immigration-friendly and accepts numerous visiting foreigners (29). Therefore, migration poses a major challenge and crisis in malaria control.

Participants' experiences were indicative of positive perceptions and knowledge, which is consistent with the results of a study on both Afghan and Iranian communities and revealed signs of awareness about the symptoms and the transmission route of malaria in both groups and their belief about malaria as a preventable disease and mosquito nets as an effective prevention method (26). Although most of the participants in this study had enough knowledge about the causes of malaria incidence and the role of mosquito nets in its transmission, very few of them used mosquito nets. The negative perception of participants appears to pertain to their lack of attention to personal protection, which is consistent with the results obtained on women in S and B province (30). Thus, there is an urgent call for updated information on key sociocultural 
and socioeconomic indicators of malaria to control strategies (31).

Access to facilities can play a major role in reducing the local transmission of malaria. Access to electricity and facilities reduces malaria transmission significantly in rural areas and may even end the transmission of malaria in some cases (29). Economic status can also significantly correlate with the number of malaria cases as reported in Ghana (32). In a county in the south of Iran, there was a report about a significantly higher number of malariainfected Afghans recently moved to Larestan county (21). Owing to a large number of Afghan and Pakistani migrants in $S$ and $B$ province and their significant role in malaria transmission among the local population, it is expected that malaria cases among the local population increases and epidemiological classification of malaria within the health system changes.

Health monitoring of migrant and mobile population from neighboring countries and providing their basic needs seems to be necessary. The results of the present study are also indicative of negative enablers, including the health houses' failure to distribute prevention tools among the region's temporary residents, the extremely poor hygiene among these groups, and the poor infrastructure in place in the country's rural and border areas.

People's low motivation for disease prevention due to the difficulties of daily life, illegal cross-border movement, and strict border control by police were discerned in this study as negative nurturers. Apart from traveling to and from the neighboring countries, the local Iranian Baluch residents also tend to make a family or go on work trips to neighboring countries, which further contribute to malaria infection rates. Malaria infection cannot be prevented only by closing borders and preventing crossborder movement; rather, it is important to take into account lifestyles, attitudes, behaviors, and cultural habits in the development of malaria control plans.

All human behaviors reflect the culture and values of a given society to varying degrees and social norms and standards of conduct also restrict individual choices (33). Some of the cultural impediments observed in this study include the false beliefs about the usefulness of herbal medicines for the treatment of the disease (negative perception), the wrong attitude of being protected from the disease due to job conditions (negative perception), the belief in destiny and God's will for the incidence of diseases (negative enabler) and eating native plants for preventing the disease (existential nurturer). Health planners should take into account the cultural condition of the region for designing, implementing, and evaluating prevention programs (34). Substantial and significant investments are needed to coordinate national malaria control programs for achieving the goals of the $\mathrm{WHO}(35)$.

\subsection{Conclusions}

Improving malaria control measures requires careful consideration of the local beliefs and actions because society's culture is a potential factor. Furthermore, cultural differences of immigrants affect the incidence of malaria in border regions. Therefore, local health workers familiar with the culture of the region can help the residents of this area by providing education on malaria and prevention methods. However, simply providing education and prevention tools cannot eradicate malaria from this region. Improving the residents' cultural sensitivity via health promotion programs may lead to behavior changes depending on the cultural framework in place and the current conditions.

\section{Acknowledgments}

Hereby, the authors would like to express their gratitude to Zahedan University of Medical Sciences, Health Promotion Research Center and the Provincial Health Center, and the healthcare workers in Iranshahr, Saravan, and Chabahar for their cooperation.

\section{Footnotes}

Conflict of Interests: The authors declared that there was no conflict of interests.

Ethical Approval: IR.ZAUMS.REC.1395.246.

Funding/Support: This project has been financially supported by Center for Communicable Disease Control and Prevention, Ministry of Health and Medical Education of Iran.

\section{References}

1. Roll Back Malaria; World Health Organization; United Nations Children's Fund (UNICEF). World malaria report. World Health Organization; 2005. Report No. WHO/HTM/MAL/2005.1102.

2. WHO Expert Committee on Malaria. WHO Expert Committee on Malaria, report 2010. Geneva, Switzerland; 2010.

3. International Organization for Migration (IOM). A global report on population mobility and malaria: Moving towards elimination with migration in mind. Geneva, Switzerland; 2013.

4. World Health Organization. World malaria report. Geneva, Switzerland; $2011.3 \mathrm{p}$.

5. World Health Organization. World malaria report 2017. 2017.195 p.

6. Halimi M, Farajzadeh M, Delavari M, Bagheri H. [Climatic survey of malaria incidence in Iran during 1971-2005].J Sch Publ Health Inst Publ Health Res. 2014;12(1):1-11. Persian.

7. Edrissian GH. [Malaria in Iran: Past and present situation]. Iran J Parasitol. 2006;1(1):1-14. Persian. 
8. World Health Organization. World malaria report 2008. Switzerland: World Health Organization; 2008. 6 p.

9. Mozaffari GH, Mostofialmammaleki R, Hashemi A. [Bioclimatic analysis of the malaria disease outbreak in Chabahar city]. Geogr Space. 2012;12(38):21-37. Persian.

10. Raeisi A, Nikpoor F, Ranjbar K, Faraji LM. [The trend of malaria in I.R. Iran from 2002 to 2007]. Hakim Med J. 2009;12(1):35-41. Persian.

11. Jadgal KH, Zareban I, Rakhshani F, Shahrakipour M, Sepehrvand B, Alizadeh Sivaki H. The effect of health education according to the theory of planned behavior on malaria preventive behavior in rural men of Chabahar. J Research Health. 2012;2(2):237-46.

12. Prosper O, Ruktanonchai N, Martcheva M. Assessing the role of spatial heterogeneity and human movement in malaria dynamics and control.J Theor Biol. 2012;303:1-14. doi:10.1016/j.jtbi.2012.02.010. [PubMed: 22525434].

13. Martens P, Hall L. Malaria on the move: human population movement and malaria transmission. Emerg Infect Dis. 2000;6(2):103-9. doi: 10.3201/eid0602.000202. [PubMed: 10756143]. [PubMed Central: PMC2640853].

14. Mascarello M, Allegranzi B, Angheben A, Anselmi M, Concia E, Lagana $S$, et al. Imported malaria in adults and children: Epidemiological and clinical characteristics of 380 consecutive cases observed in Verona, Italy. J Travel Med. 2008;15(4):229-36. doi: 10.1111/j.17088305.2008.00204.x. [PubMed: 18666922].

15. Wiwanitkit V. Rate of malarial infection among foreigners in a tertiary hospital of Thailand: change of epidemiology and importance of travel medicine (1996-2005). J Vector Borne Dis. 2007;44(3):219-22. [PubMed: 17896625].

16. Salvado E, Pinazo MJ, Munoz J, Alonso D, Naniche D, Mayor A, et al. [Clinical presentation and complications of Plasmodium falciparum malaria in two populations: Travelers and immigrants]. Enferm Infecc Microbiol Clin. 2008;26(5):282-4. [PubMed: 18479645].

17. Caraballo A, Rodriguez-Acosta A. Notes about the impact of human seasonal migration on malaria spreading in rural Venezuela. Roum Arch Microbiol Immunol. 2004;63(3-4):245-52. [PubMed: 17240793].

18. Matteelli A, Volonterio A, Gulletta M, Galimberti L, Maroccolo S, Gaiera $\mathrm{G}$, et al. Malaria in illegal Chinese immigrants, Italy. Emerg Infect Dis. 2001;7(6):1055-8. doi: 10.3201/eid0706.010628. [PubMed: 11747743]. [PubMed Central: PMC2631896].

19. Sartipi M, Khosravi A, Khalaji K, Shamsipour M, Kazemi-galougahi MH, Sakeni M, et al. [Examining the risk factors of malaria: A matched casecontrol study]. Nurse and Physician within War. 2014;2(2):10-6. Persian.

20. Comm SA, Noorhidayah I, Osman A. [Seasonal migration: A case control study of malaria prevention in Sabah]. Med J Malaysia. 1999;54(2):200-9. Malay. [PubMed:10972030].

21. Forootani MR. [Malaria infestation in foreign immigrants residing Larestantownship in 2003-2004]. J Hormozgan Univ Med Sci. 2007;3:229-36. Persian.

22. Nejati J, Ansari Moghadam AR, Keyhani A, Tabatabai SM. [Effects of immigration on malaria incidence and its foci classification]. J Hormoz- gan Univ Med Sci. 2011;16(4):284-91. Persian

23. World Health Organization. World malaria report on 2010. 2010.

24. Rowland M, Webster J, Saleh P, Chandramohan D, Freeman T, Pearcy $\mathrm{B}$, et al. Prevention of malaria in Afghanistan through social marketing of insecticide-treated nets: Evaluation of coverage and effectiveness by cross-sectional surveys and passive surveillance. Trop Med Int Health. 2002;7(10):813-22. [PubMed: 12358615].

25. Basseri HR, Raeisi A, Holakouie K, Shanadeh K. Malaria prevention among Afghani refugees in a malarious area, southeastern Iran Bull Soc Pathol Exot. 2010;103(5):340-5. doi: 10.1007/s13149-010-0050-3. [PubMed: 20526828].

26. Shahandeh K, Basseri HR, Shojaeizadeh E. Using the cultural model to plan intervention for malaria control in immigrants and native communities in endemic area, earmarked for malaria elimination southeastern Iran. Malaria J. 2012;11(S1). doi:10.1186/1475-2875-11-s1-p132.

27. Shahandeh K, Basseri HR, Sharifzadeh Y. An application of cultural model to assess and compare malaria prevention among Afghani migrant and Baluchi resident in the endemic area, southeastern Iran.J Immigr Minor Health. 2014;16(1):102-10. doi: 10.1007/s10903-013-9850-4. [PubMed: 23775110].

28. Safari M, Shojaei-Zadeh D, Ghofranipour F, Heydarnia AR, Pakpur A [Theories, models and methods of health education and health promotion]. Tehran: Asaresobhan; 2009. Persian.

29. Poudat A, Ladoni H, Raeisi A. [Possible factors affecting the malaria situation in the city of Bandar Abbas in 1999-2002].J Hormozgan Univ Med Sci. 2006;2:101-10. Persian.

30. Rakhshani F, Ansari Moghadam AR, Alemi R, Moradi A. Knowledge, perceptions and prevention of malaria among women in Sistan va Baluchestan, Islamic Republic of Iran. E Mediterr Health J. 2003;9(3).

31. Karunamoorthi $K$, Bekele $M$. Changes in malaria indices in an Ethiopian health centre: A five year retrospective analysis. Health Scope. 2012;1(3):118-26. doi: 10.5812/jhs.7076.

32. Krefis AC, Schwarz NG, Nkrumah B, Acquah S, Loag W, Sarpong N, et al. Principal component analysis of socioeconomic factors and their association with malaria in children from the Ashanti Region, Ghana. Malar J. 2010;9:201. doi: 10.1186/1475-2875-9-201. [PubMed: 20626839]. [PubMed Central: PMC2914064].

33. Champion VL, Monahan PO, Springston JK, Russell K, Zollinger TW, Saywell RM Jr, et al. Measuring mammography and breast cancer beliefs in African American women. J Health Psychol. 2008;13(6):827-37. doi: 10.1177/1359105308093867. [PubMed: 18697896]. [PubMed Central: PMC2902247].

34. Tabatabai M, Dorosti AR, Keshavarz A. [Review case-control risk factors of obesity in primary school pupils monitoring]. J Inst Health Sci Univ. 2004;9(1):27-19. Persian.

35. Mohammadi M, Ansari-Moghaddam A, Raiesi A, Rakhshani F, Nikpour $F$, Haghdost A, et al. Baseline results of the first malaria indicator survey in Iran at household level. Malar J. 2011;10:277. doi: 10.1186/14752875-10-277. [PubMed: 21939505]. [PubMed Central: PMC3184285]. 